Gut, 1989, 30, 397-403

\title{
Serial computed tomography scanning in acute pancreatitis: a prospective study
}

\author{
N J M LONDON, J P NEOPTOLEMOS, J LAVELLE, I BAILEY, \\ AND D JAMES
}

From the Departments of Surgery and Radiology, Clinical Sciences Building, Leicester Royal Infirmary, Leicester

SUMmary One hundred and two patients with acute pancreatitis had abdominal computed tomography (CT) scans within 72 hours of admission, at one week and at six weeks. Twenty eight attacks were clinically severe, 74 clinically mild. Ninety three $(91 \%)$ admission scans, $85(84 \%)$ one week scans, and $52(51 \%)$ six week scans were abnormal. The aetiology of the pancreatitis could be inferred from $28(27 \%)$ of admission scans, the CT sign of fatty liver having a sensitivity of $21 \%$ and specificity of $\mathbf{1 0 0} \%$ for alcoholic aetiology. The sensitivity of CT for gall stone aetiology was 34\%, specificity $100 \%$. The pancreatic size indices (max anteroposterior measurement of head $\times$ max anteroposterior measurement of body) of those patients with severe attacks were significantly greater than those with mild attacks on admission, at one week and at six weeks $(p<0 \cdot 004)$. Fourteen pseudocysts were detected by CT, five (36\%) of which were clinically apparent. The pseudocyst size indices (max anteroposterior $\times$ max transverse measurement) of the pseudocysts which were clinically apparent were significantly greater than those which were not apparent $(p<0 \cdot 01)$ and only those pseudocysts with a size index $\geqslant 15 \mathrm{~cm}^{2}$ required treatment.

Although there have been numerous studies of CT scanning in acute pancreatitis, there have not been any reports of serial CT scanning of the disease. The purpose of this prospective study was to obtain CT scans of patients with acute pancreatitis on admission to hospital, at one week, and at six weeks and to thereby document the natural history of the local disease process. We also wished to study the ability of CT to diagnose acute pancreatitis and its local complications and to compare the serial CT appearances of the pancreata of those patients with mild and severe attacks.

\section{Methods}

PATIENTS

Patients admitted to the Leicester Royal Infirmary with a diagnosis of acute pancreatitis during the period May 1984 to December 1986 were referred for abdominal CT scanning. The diagnosis of acute

Address for correspondence: Mr N J M London, Dept of Surgery. L.eicester Royal Infirmary, PO Box 65, Leicester LE2 7LX.

Accepted for publication 25 August 1988. pancreatitis was based on a serum amylase of greater than $1000 \mathrm{IU} / \mathrm{l}$ (Phadebas Method) in the presence of a compatible clinical picture. Computed tomography scans were done within 72 hours of admission, at one week and at six weeks. All scans were done on a GE 8800 scanner and reported 'blind' by a single consultant radiologist. The admission scan consisted of a plain abdominal scan followed by a contrastenhanced scan taking $10 \mathrm{~mm}$ contiguous cuts during an intravenous infusion of $100 \mathrm{ml}$ Niopam 370 . The one week and six week scans were not contrast enhanced. Pancreatic enhancement on the admission scan was defined as increased, normal or decreased compared with the enhancement of the liver and spleen. It was noted for all scans whether there was loss of peripancreatic tissue planes and the maximum anteroposterior measurement (in centimetres) of the pancreatic head, body, and tail were recorded. These measurements were taken opposite the right hand border of the lumbar vertebrae, the left hand border of the aorta and the left renal hilum respectively. The measurements from 50 scans were repeated by an independent observer in order to determine their reproducibility. The 'pancreatic size index' was 
calculated as previously described ${ }^{1}$ (the product of the head and body measurements, $\mathrm{cm}^{2}$ ). The visualisation of the pancreas was recorded as good, fair, or poor. The presence or absence of gall stones and any other pertinent abnormalities were noted. If a pancreatic pseudocyst was present then the maximum anteroposterior and transverse measurements were taken (centimetres). The product of these two measurements was defined as the 'pseudocyst size index'. A severe outcome from pancreatitis was defined as death or a major systemic or local complications. The diagnosis of gall stone pancreatitis was based on the findings of gall stones at laparotomy, necropsy, or their unequivocal detection by ultrasonography or ERCP. The absence of gall stones was based on at least three ultrasound examinations and one ERCP.

Continuous variables were analysed by the twotailed Mann-Whitney U test for unpaired data and by the Wilcoxon's matched-pairs signed-rank test for paired data. Discrete variables were analysed by the $\chi^{2}$ test with Yates's correction when the expected number of observations was small. Sensitivity and specificity were calculated as described by McNeil et al. ${ }^{2}$ Statistical significance was assumed to be $\mathrm{p}<0 \cdot 05$.

\section{Results}

One hundred and fifty two patients with acute pancreatitis were admitted to the Leicester Royal Infirmary during the 31 month period of the study. One hundred and two patients $(67 \%)$ completed a series of three abdominal CT scans. All the 'admission scans' were obtained within 72 hours. The 'one week' scans were done seven to 10 days after admission, the 'six week' scans at 40-46 days. The details of all patients admitted during the study period and of those patients who did and did not complete a series of three CT scans are given in Table 1. The major complications of those patients with severe attacks of pancreatitis and a comparison of the details of the severe and mild groups amongst the 102 patients who had a series of three CT scans are given in Tables 2 and 3. Figure 1 and Tables 4 and 5 document the CT findings on admission, at one and at six weeks. It can be seen that only six $(6 \%)$ patients had CT scans which remained normal for admission through to six weeks. All six patients had an admission serum amylase of $>2000$ IU/l, the aetiology of the pancreatitis was biliary in three, idiopathic in two and alcohol in one. Two of the three patients with biliary pancreatitis had an endoscopic sphincterotomy for common bile duct stones. There did not appear to be any doubt about the clinical diagnosis of pancreatitis in any of these six patients.

The aetiology of pancreatitis could be inferred
Table 1 Details of all patients admitted during the study period and of those who did and did not have a series of three CT scans

\begin{tabular}{lccl}
\hline \multicolumn{5}{c}{ All patients } & Scanned $\times 3$ & Not scanned $\times 3$ \\
\hline Patients (n) & $152(100)$ & $102(67)$ & $50(33)$ \\
Mediä age (range), yrs & $64(19-90)$ & $62(25-90)$ & $63(19-88)$ \\
Clinical severity & & & \\
$\quad$ Severe & $4530)$ & $28^{*}(27)$ & $17^{*}(34)$ \\
Mild & $107(70)$ & $74(73)$ & $33(66)$ \\
Deaths & $13(9)$ & $1 \dagger(1)$ & $12 \dagger(24)$ \\
Men & $77(51)$ & $56(55)$ & $21(42)$ \\
Women & $75(49)$ & $46(45)$ & $29(58)$ \\
Aetiology of pancreatitis & & & \\
Biliary & $90(59)$ & $62(60)$ & $28(56)$ \\
Alcohol & $32(21)$ & $19(18)$ & $13(26)$ \\
Idiopathic & $16(11)$ & $10(12)$ & $6(12)$ \\
Ca pancreas & $3(2)$ & $3(3)$ & 0 \\
Post E sphincterotomy & $3(2)$ & $3(3)$ & 0 \\
Hyperlipidemia & $2(1 \cdot 3)$ & $2(2)$ & 0 \\
Polyarteritis nodosa & $1(0 \cdot 8)$ & $1(1)$ & 0 \\
Parathyroidectomy & $2(1 \cdot 3)$ & $1(1)$ & $1(2)$ \\
Systemic lupus & $1(0 \cdot 8)$ & 0 & $1(2)$ \\
Trauma & $1(0 \cdot 8)$ & 0 & $1(2)$ \\
\hline
\end{tabular}

Figures in parentheses are percentages.

*Not significant, $\chi: \dagger p<0 \cdot 001, \chi^{2}$.

Table 2 Major complications of patients with severe attacks of pancreatitis

\begin{tabular}{ll}
\hline Complication & Patients $(n)$ \\
\hline Respiratory failure & 8 \\
Renal failure & 4 \\
Pancreatic abscess & $5(1)^{*}$ \\
Pseudocyst & 5 \\
Pneumonia & 3 \\
Pseudo-obstruction & 1 \\
Duodenal obstruction & 1 \\
D. intravascular coagulation & 1 \\
\hline
\end{tabular}

(1)* One patient with a pancreatic abscess died.

Table 3 Comparison of the details of those patients with mild and severe attacks of pancreatitis amongst the 102 patients who had three CT scans

\begin{tabular}{lll}
\hline & \multicolumn{1}{l}{ Clinical severity } \\
\cline { 2 - 3 } & Severe $(n=28)$ & Mild $(n=74)$ \\
\hline Patients (n) & $28(27 \cdot 4)$ & $74(72 \cdot 6)$ \\
Median age (range), yrs & $68 \cdot 5(27 \cdot 0-90 \cdot())$ & $58 \cdot(125 \cdot()-90 \cdot())$ \\
Men & $12(43)$ & $44(59)$ \\
Women & $16(57)$ & $30(51)$ \\
Aetiology of pancreatitis & & \\
$\quad$ Biliary & $14(50)$ & $48(65)$ \\
$\quad$ Alcohol & $8(29)$ & $11(15)$ \\
Idiopathic & $1(3)$ & $7(9)$ \\
Others & $5(18)$ & $8(11)$ \\
\hline
\end{tabular}

Figures in parentheses are percentages. 


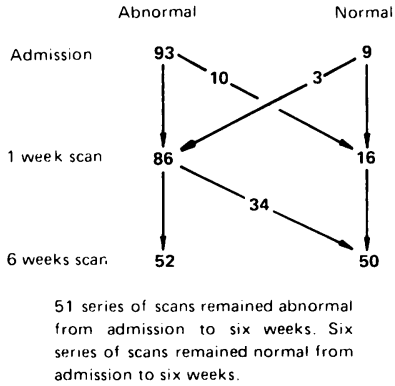

Fig. 1 Number of abnormal and normal CT scans on admission, at one week and at six weeks $(n=102)$.

from $28(27 \%)$ of admission scans. The sensitivity for gall bladder stones was $21 / 62=34 \%$, the specificity $40 / 40=100 \%$. The sensitivity for common bile duct stones was one of $15=7 \%$, the specificity $87 / 87=$ $100 \%$. The CT sign of fatty liver had a sensitivity of four of $19=21 \%$ for alcoholic aetiology, specificity $=$ $83 / 83=100 \%$. One case of lymphoma was diagnosed by $\mathrm{CT}$ as a result of para-aortic lymphadenopathy and two out of three cases of carcinoma of the pancreas were diagnosed by CT on the basis of liver metastases. The sensitivities of the one week and six week CT scans for gall bladder stones were 29 and $30 \%$ respectively. The specificity was $100 \%$ on both occasions.

Tables 6 and 7 compare the CT findings of the patients with mild and severe attacks of pancreatitis, including a comparison of pancreatic size measurements. When 50 pancreatic size measurements were repeated by a second observer the median (range) difference between his measurements and those of the original radiologist was $0.5(0.0-1.4) \mathrm{cm}, \mathrm{p}=0.8$ Wilcoxon's matched-pairs signed rank test. The changes in pancreatic size indices of the severe and mild groups are shown in Figure 2.

Table 4 Computed tomography findings of the 102 patients who had a complete series of three scans

\begin{tabular}{|c|c|c|c|}
\hline & $\begin{array}{l}\text { Admission } \\
\text { scan }\end{array}$ & \multicolumn{2}{|c|}{ One week scan Six week scan } \\
\hline \multicolumn{4}{|c|}{ Visualisation of pancreas } \\
\hline Good & $94(92)$ & $97(95)$ & $97(95)$ \\
\hline Fair & $8(8)$ & $5(5)$ & $4(4)$ \\
\hline Poor & $0(0)$ & $0(0)$ & $1(1)$ \\
\hline Abnormal scan & $93(91)$ & $86(84)$ & $52(51)$ \\
\hline Normal scan & $9(0)$ & $16(16)$ & $50(49)$ \\
\hline \multicolumn{4}{|c|}{ Pancreatic enhancement } \\
\hline Decreased & $65(64)$ & Not relevant & Not relevant \\
\hline Normal & $37(36)$ & & \\
\hline \multicolumn{4}{|c|}{ Peripancreatic planes } \\
\hline Preserved & $34(33)$ & $57(56)$ & $78(76)$ \\
\hline Lost & $68(67)$ & $45(44)$ & $24(24)$ \\
\hline
\end{tabular}

Figures in parentheses are percentages.
There were five patients who developed pancreatic abscesses. Three of these were diagnosed by CT, two on the basis of metastatic hepatic abscesses and one on the basis of adjacent abdominal wall oedema. Intrapancreatic gas was not seen in any of the five cases of pancreatic abscess. There were 14 pseudocysts diagnosed by CT, five $(36 \%)$ of which were clinically apparent. The timing of appearance and regression of these pseudocysts is illustrated in Figure 3 . The pseudocyst size indices of the pseudocysts which were clinically apparent were significantly greater than those which were not $(\mathrm{p}<0 \cdot 01$, Mann-

Table 5 Details of abnormal admission, one week and six weeks scans

\begin{tabular}{llll}
\hline & $\begin{array}{l}\text { Admission } \\
\text { scan }\end{array}$ & & One week scan Six week scan \\
\hline Type of abnormality & $(\mathrm{n}=93)$ & $(\mathrm{n}=86)$ & $(\mathrm{n}=52)$ \\
LOTP $+\downarrow \mathrm{E}+\uparrow$ size & 48 & Not relevant & Not relevant \\
LOTP $+\uparrow$ size & 17 & 46 & 19 \\
$\uparrow$ size $+\downarrow \mathrm{E}$ & 13 & Not relevant & Not relevant \\
$\uparrow$ size only & 13 & 40 & 33 \\
$\downarrow$ E only & 2 & Not relevant & Not relevant \\
LOTP only & 0 & 0 & 0 \\
Site of pancreatic & $(\mathrm{n}=91)$ & $(\mathrm{n}=86)$ & $(\mathrm{n}=52)$ \\
enlargement & & & \\
Head only (H) & 9 & 7 & 10 \\
Body only (B) & 0 & 0 & 0 \\
Tail only (T) & 0 & 6 & 1 \\
Head plus body $(\mathrm{H}+\mathrm{B})$ & 3 & 2 & 1 \\
Body plus tail (B+T) & 4 & 1 & 0 \\
Diffuse (H+B $+\mathrm{T})$ & 75 & 70 & 40 \\
\hline
\end{tabular}

LOTP $=$ Loss of peripancreatic tissue planes.

$\downarrow E=$ Decreased pancreatic enhancement.

$\uparrow$ size $=$ Increase in size of pancreas.

Table 6 Comparison of CT findings in the mild and severe groups

\begin{tabular}{|c|c|c|c|}
\hline & \multicolumn{3}{|c|}{ Clinical severity } \\
\hline & $\begin{array}{l}\text { Severe } \\
(n=28)\end{array}$ & $\begin{array}{l}\text { Mild } \\
(n=74)\end{array}$ & $p$ \\
\hline \multicolumn{4}{|l|}{ Admission scan } \\
\hline Abnormal & $28(100)$ & $65(88)$ & \\
\hline Normal & $0(0)$ & $9(12)$ & $0 \cdot 1$ \\
\hline Normal enhancement & $6(21)$ & $31(42)$ & \\
\hline Decreased enhancement & $22(79)$ & $43(58)$ & $0 \cdot 1$ \\
\hline Normal peripancreatic tissue planes & $5(18)$ & $32(43)$ & \\
\hline Loss of peripancreatic tissue planes & $23(82)$ & $42(57)$ & $0 \cdot 05$ \\
\hline \multicolumn{4}{|l|}{ One week scan } \\
\hline Abnormal & $26(93)$ & $60(81)$ & \\
\hline Normal & $2(7)$ & $14(19)$ & $0 \cdot 1$ \\
\hline Normal peripancreatic tissue planes & $4(36)$ & $52(70)$ & \\
\hline Loss of peripancreatic tissue planes & $24(64)$ & $22(30)$ & 0.0001 \\
\hline \multicolumn{4}{|l|}{ Six weeks scan } \\
\hline Abormal & $17(61)$ & $35(47)$ & \\
\hline Normal & $11(39)$ & $39(53)$ & $0 \cdot 1$ \\
\hline Normal peripancreatic tissue planes & $14(50)$ & $69(93)$ & 0000 \\
\hline Loss of peripancreatic tissue planes & $14(50)$ & $5(7)$ & $0.0(0) 1$ \\
\hline
\end{tabular}

p values by $\chi^{2}$ test. 
Table 7 Comparison of pancreatic size measurements of severe and mild groups

\begin{tabular}{|c|c|c|c|}
\hline & \multicolumn{2}{|l|}{ Clinical severity } & \multirow[b]{2}{*}{$p$} \\
\hline & Severe $(n=28)$ & Mild $(n=74)$ & \\
\hline \multicolumn{4}{|l|}{ Admission scan } \\
\hline Head $(\mathrm{cm})$ & $3 \cdot 9(2 \cdot 0-7 \cdot 0)$ & $2 \cdot 8(1 \cdot 2-5 \cdot 8)$ & $0 \cdot 0010$ \\
\hline Body $(\mathrm{cm})$ & $2 \cdot 9(1 \cdot 7-6 \cdot 8)$ & $1 \cdot 8(1 \cdot 2-3 \cdot 8)$ & 0.0010 \\
\hline Tail $(\mathrm{cm})$ & $2 \cdot 6(1 \cdot 5-4 \cdot 7)$ & $1 \cdot 9(1 \cdot 2-5 \cdot 0)$ & $0 \cdot 0020$ \\
\hline Head $\times$ body $\left(\mathrm{cm}^{2}\right)$ & $12 \cdot 6(3 \cdot 4-47 \cdot 6)$ & $6 \cdot 2(1 \cdot 4-22 \cdot 0)$ & 0.0001 \\
\hline \multicolumn{4}{|c|}{ One week scan } \\
\hline Head $(\mathrm{cm})$ & $4 \cdot 0(2 \cdot 0-6 \cdot 5)$ & $3 \cdot 0(1 \cdot 0-6 \cdot 0)$ & $0 \cdot 0001$ \\
\hline Body $(\mathrm{cm})$ & $3 \cdot 3(2 \cdot 0-8 \cdot 5)$ & $2 \cdot 0(1 \cdot 0-6 \cdot 0)$ & $0 \cdot 0008$ \\
\hline Tail $(\mathrm{cm})$ & $3 \cdot 0(1 \cdot 5-8 \cdot 0)$ & $2 \cdot 0(1 \cdot 0-5 \cdot 0)$ & $0 \cdot 0020$ \\
\hline Head $\times$ body $\left(\mathrm{cm}^{2}\right)$ & $12 \cdot 1(4 \cdot 0-55 \cdot 2)$ & $6 \cdot 3(1 \cdot 0-30 \cdot 0)$ & $0 \cdot 0004$ \\
\hline \multicolumn{4}{|c|}{ Six weeks scan } \\
\hline Head $(\mathrm{cm})$ & $3 \cdot 0(1 \cdot 5-7 \cdot 0)$ & $2 \cdot 9(0 \cdot 9-8 \cdot 0)$ & $0 \cdot 0090$ \\
\hline Body $(\mathrm{cm})$ & $2 \cdot 8(1 \cdot 2-6 \cdot 0)$ & $2 \cdot 0(0 \cdot 5-7 \cdot 0)$ & $0 \cdot 0050$ \\
\hline Tail $(\mathrm{cm})$ & $3 \cdot 0(1 \cdot 0-6 \cdot 0)$ & $2 \cdot 0(0 \cdot 5-6 \cdot 0)$ & 0.0006 \\
\hline Head $\times$ body $\left(\mathrm{cm}^{2}\right)$ & $8 \cdot 5(2 \cdot 2-30 \cdot 0)$ & $5 \cdot 5(0 \cdot 5-56 \cdot 0)$ & $0 \cdot 0040$ \\
\hline
\end{tabular}

Values are median (range); head $\times$ body $=$ pancreatic size index; $p$ values by Mann-Whitney $U$ test.

Whitney $U$ test) (Table 8 ). Only those pseudocysts with a size index of $\geqslant 15 \mathrm{~cm}^{2}$ required treatment.

\section{Discussion}

Since the first description of the CT appearances of the pancreas by Haaga et $a l^{3}$ there have been numerous reports concerning the CT appearances of

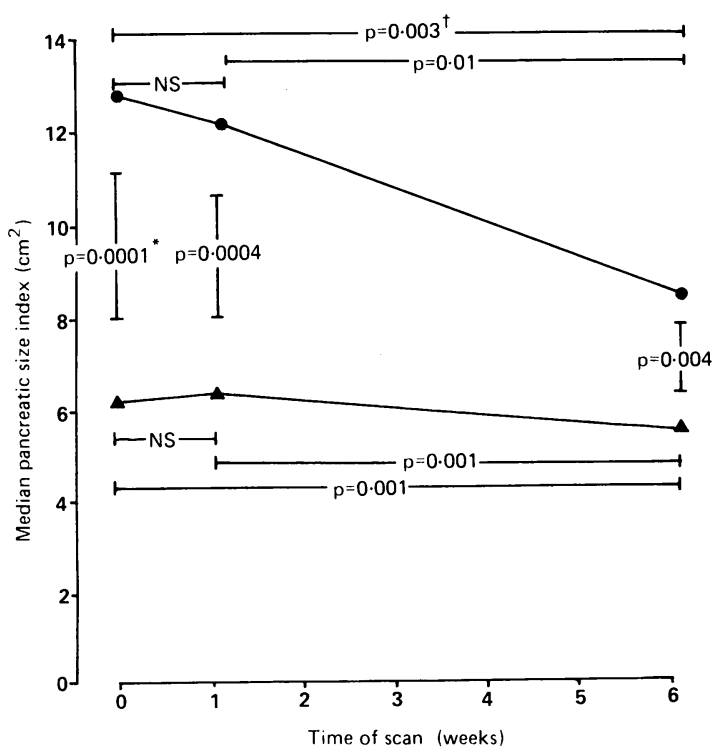

Fig. 2 Changes in pancreatic size index (product of head and body measurements) for patients with severe (O) and mild $(\mathbf{\Delta})$ attacks of pancreatitis. Values are median, for clarity ranges are not included, see Table 7. *Mainn-Whitney $U$ test, $¥$ Wilcoxon's matched-pairs signed rank test.

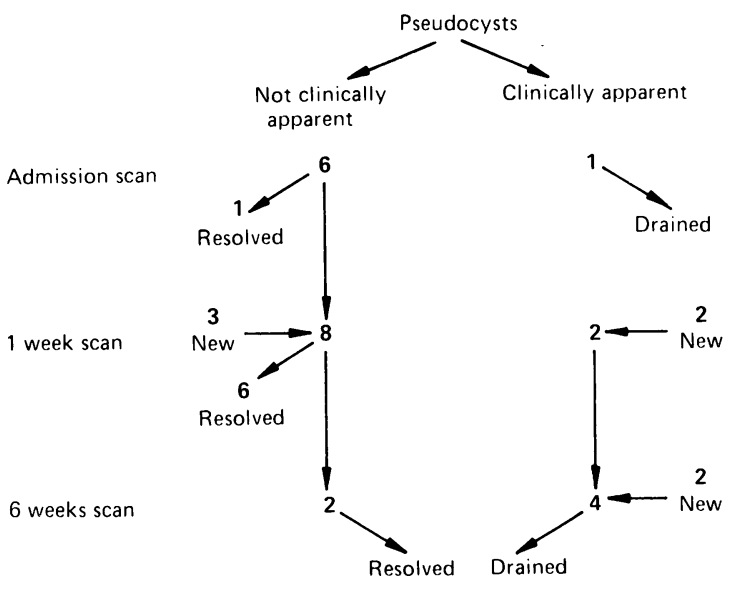

Fig. 3 Timing of appearance and resolution of pseudocysts shown by CT. There were a total of 14 pseudocysts.

pancreatitis and its complications. There have not, however, been any previous studies designed specifically to follow the natural history of pancreatitis by serial CT scanning. The age-sex distribution, aetiology of pancreatitis, proportion of severe attacks $(27 \%)$, incidence of clinically apparent pseudocysts (5\%), and abscesses (5\%) amongst the 102 patients who had a series of three CT scans are similar to those of other studies of pancreatitis from the UK. ${ }^{+10}$ This suggests that our patients were not a selected group. The mortality rate in our study is inevitably low because patients who were moribund on admission were not referred for CT scanning and the majority of deaths occurred within six weeks of admission thereby precluding a complete series of scans. The proportion of severe attacks amongst the patients who were and were not scanned was not significantly different indicating that although the mortality rate was lower in the group of patients who were scanned, this group was not selected in terms of overall disease severity.

We found that the visualisation of the pancreas was good in $95 \%$ of scans. This compares with good

Table 8 Pseudocyst size indices of pseudocysts which were and were not clinically apparent

\begin{tabular}{|c|c|c|c|c|}
\hline & \multicolumn{2}{|c|}{ Clinically apparent } & \multicolumn{2}{|c|}{ Not clinically apparent } \\
\hline & $(n=5)$ & & $(n=$ & \\
\hline $\begin{array}{l}\text { Pseudocyst size } \\
\text { indices }\left(\mathrm{cm}^{2}\right)\end{array}$ & $\begin{array}{l}15 \cdot 0 \\
20 \cdot() \\
3(0 \cdot() \\
4(0 \cdot 0\end{array}$ & $49 \cdot()$ & $\begin{array}{l}1 \cdot 0 \\
2 \cdot 3 \\
2 \cdot 3 \\
4 \cdot 0 \\
6 \cdot 0\end{array}$ & $\begin{array}{r}9 \cdot() \\
12 \cdot(1 \\
12 \cdot 2 \\
13 \cdot 5\end{array}$ \\
\hline
\end{tabular}

The difference between the two groups is significant. $\mathrm{p}<0.01$ Mann Whitney U test. 
visualisation in $64^{11}$ and $100 \%{ }^{12}$ in previous studies. There is general agreement that CT is superior to ultrasonography for detecting pancreatitis and its local complications ${ }^{1-1-14}$ because the often associated paralytic ileus hinders thorough ultrasonographic examination of the gland. ${ }^{15}$ it $\mathrm{A}$ wide variety of CT findings have been described in acute pancreatitis. These include enlargement of the gland, ${ }^{17-25}$ abnormal parenchymal enhancement, ${ }^{1922}$ loss of peripancreatic tissue planes, ${ }^{17-25}$ intraperitoneal or retroperitoneal fluid collections ${ }^{21-25}$ and thickening of the perirenal fascia. ${ }^{11-25}$ Ninety one per cent of our admission scans were abnormal (cf 32$100 \% 11121721222627$ ), the most frequent abnormality being a combination of loss of peripancreatic tissue planes, decreased enhancement and diffuse increase in pancreatic size. The most common form of pancreatic enlargement was a diffuse swelling of the gland $(82 \%)$ followed by swelling of the head only $(9 \%)$. This finding is in agreement with previous reports. ${ }^{1121222729}$

The sensitivity of an admission scan for the diagnosis of acute pancreatitis was $91 \%$, remarkably similar to the figure of $92 \%$ produced by Clavien et al. ${ }^{2 h} \mathrm{We}$ could not calculate the specificity of CT for the diagnosis of acute pancreatitis because we did not scan all patients admitted with abdominal pain. Eighty four per cent of scans were still abnormal at one week. This information is of clinical value because it means that there is a high chance of making a retrospective diagnosis of acute pancreatitis by CT in those patients whose serum amylase has returned to normal. Fifty one per cent of CT scans were abnormal at six weeks. This finding is in broad agreement with the findings of Hill et al ${ }^{2 \mathrm{x}}$ who noted that the CT signs of acute pancreatitis can take many weeks to clear.

Admission CT detected gall bladder stones in 34\% of patients with biliary pancreatitis. Although there have not been any previous studies of CT and the detection of gall stones in acute pancreatitis, Balthazar et al ${ }^{24}$ noted that gall stones were missed 'in a number of patients who proved to have cholelithiasis'. Ultrasonography would appear to be a more sensitive method for the detection of gall stones early in acute pancreatitis ${ }^{313.31}$ and unlike CT the sensitivity of ultrasonography for gall stones increases when the attack has settled at six weeks. ${ }^{32}$ We found that fatty infiltration of the liver which occurred in $4 \%$ of our patients had a specificity of $100 \%$ for alcoholic aetiology. This CT sign has previously been noted by Balthazar et al ${ }^{29}$ who recorded fatty infiltration of the liver in $25.3 \%$ of his patients. This relatively high incidence is presumably related to the fact that $67 \%$ of patients in his study had an alcoholic aetiology for their pancreatitis. The presence of fatty infiltration of the liver is not related to the severity of the pancreatitis. ${ }^{29}$ Abdominal lymphoma is a recognised cause of acute pancreatitis ${ }^{33}$ and the single case in our study was diagnosed by CT. Carcinoma of the pancreas is associated with acute pancreatitis in $1-2 \%$ of cases. ${ }^{3.36}$ Two of three cases of pancreatitis caused by pancreatic carcinoma in our study were diagnosed by CT on the basis of liver metastases. Other CT findings which may provide a clue to the diagnosis of underlying carcinoma include ${ }^{37}$ focal rather than diffuse pancreatic enlargement, pancreatic duct dilatation and lymphadenopathy.

The admission scan was contrast enhanced because we wished to determine whether there was decreased pancreatic enhancement in patients who went on to develop severe attacks. This decreased pancreatic enhancement in cases of pancreatitis which follow a severe course has been noted in an experimental model of pancreatitis ${ }^{3 \times 34}$ and in patients with alcoholic pancreatitis. ${ }^{+11+1}$ We found that the proportions of patients with decreased pancreatic enhancement amongst the mild and severe groups were not significantly different and would agree with Grabbe et al $^{\text {t2 }}$ that intravenous contrast agent does not help with the prediction of disease severity from an admission CT scan. Intravenous contrast has however been shown to be of value for the detection of pancreatic necrosis in patients with established severe disease. ${ }^{.11+3}$

Significantly more patients with severe pancreatitis had loss of peripancreatic tissue planes on admission, at one week and at six weeks. The correlation between the degree of extrapancreatic oedema and disease severity has been previously noted in a number of studies. $12+2629+2+17$ It has not previously been recorded that this difference persists at six weeks.

The differences in pancreatic size measurements and size indices between the mild and severe groups were highly significantly different on all three scans. It has previously been shown that the degree of pancreatic parenchymal swelling on an admission scan is of prognostic significance, ${ }^{+5+k}$ the pancreatic size measurements in these studies were visual estimates rather than actual measurements taken from the scans and they were not repeated after admission. Our study is thus the first to show that the differences in pancreatic parenchymal swelling between patients with mild and severe attacks persists at six weeks.

The incidence of clinically apparent pseudocyst in our study was $5 \%$, this figure is similar to that of previous reports ${ }^{x+4-51}(3-8 \%)$. It is not possible to meaningfully compare the incidence of CT detected pseudocysts in our study $(14 \%)$ because previous studies have examined highly selected patients. ${ }^{11}{ }^{5}$ 
All pseudocysts with a size index of $<15 \mathrm{~cm}^{2}$ resolved spontaneously, this resolution occurring in six of eight cases during the second to sixth week after the onset of the attack of pancreatitis. On the basis of these findings we would suggest that pseudocysts incidentally detected by CT should have their size index calculated. Those with an index of $<15 \mathrm{~cm}^{2}$ are likely to resolve whilst those with an index $\geqslant 15 \mathrm{~cm}^{2}$ should have regular CT or ultrasonographic follow up as they are likely to enlarge and require treatment.

There were five cases of pancreatic abscess in our study, three of which were diagnosed on the basis of $\mathrm{CT}$ findings alone, the remaining two did not have pathognomonic CT signs of pancreatic abscess but were diagnosed on the combination of clinical and CT findings. None of our patients had intrapancreatic gas. A review of the literature on pancreatic abscess and intrapancreatic gas seen on $\mathrm{CT}^{21-23262953-58}$ shows that intrapancreatic gas occurred in 47 of 136 abscesses (35\%). Intrapancreatic gas is not, however, pathognomonic of pancreatic abscess because it also occurs in pseudocystenteric fistulae..$^{215456.57}$ If the clinical picture and CT signs are highly suggestive of pancreatic abscess then the diagnosis should be confirmed by CT guided percutaneous needle aspiration. ${ }^{58}$ It has been suggested that retroperitoneal air seen on CT early in the course of acute pancreatitis, even though not pathognomonic of pancreatic abscess is an indication for urgent laparotomy. ${ }^{26}$ Other authors, however, stress that CT guided percutaneous aspiration should be carried out to confirm the diagnosis of abscess before surgery..$^{53}$

This is the first study to follow the natural history of the local disease process in acute pancreatitis by $\mathrm{CT}$ scanning. We have found that CT is highly sensitive for the diagnosis of acute pancreatitis and that the aetiology of pancreatitis could be inferred from $27 \%$ of admission scans. The chance of making a retrospective diagnosis of pancreatitis by CT at one week was $84 \%$. There were highly significant differences between the CT appearances of patients with clinically mild and severe attacks and these differences persisted at six weeks. Finally, $36 \%$ of pseudocysts seen on CT were clinically apparent and only those with a size index of $\geqslant 15 \mathrm{~cm}^{2}$ required treatment. In conclusion, although we would not recommend routine serial CT scanning of all patients with acute pancreatitis this study has provided important information concerning the natural history of the local disease process, and contributes to the interpretation of the CT findings in patients with established severe disease.

We are indebted to the consultant surgeons at the Leicester Royal Infirmary for permitting us to study their patients. We would like to thank Dr D Shaw for statistical advice and Mrs Denise Jarvis for typing the manuscript.

\section{References}

1 London NJM, Neoptolemos JP. Lavelle J, Bailey I, James D. Admission abdominal CT and prediction of severity of acute pancreatitis [Abstract]. Gut 1988; 29: A735.

2 McNeil BJ, Kceler E, Adelstein SJ. Primer on certain elements of medical decision marking. $N$ Engl J Med 1975; 293: 211-5.

3 Haaga JR, Alfidi RJ, Zclch MG, et al. Computed tomography of the pancreas. Radiology 1976; 120: $585-$ 95.

4 MRC Multicentre Trial. Death from acute pancreatitis Lancet 1977; ii: 632-5.

5 Leese T, Holliday M, Heath D, Hall AW, Bell PRF. Multicentre clinical trial of low volume fresh frozen plasma therapy in acute pancreatitis. BrJ Surg 1987; 74: 907-11.

6 Cooper MJ, Williamson RCN, Pollock AV. The role of peritoncal lavage in the prediction and treatment of severe acute pancreatitis. Ann R Coll Surg Engl 1982; 64: $422-7$.

7 De Bolla AR, Obeid ML. Mortality in acute pancreatitis. An R Coll Surg Engl 1984; 66: 184-6.

8 Imrie CW, Benjamin IS, Ferguson JC, et al. A singlecentre double-blind trial of Trasylol therapy in primary acute pancreatitis. BrJ Surg 1978; 65: 337-41.

9 Trapnell JE, Duncan EHL. Patterns of incidence in acute pancreatitis. $\mathrm{Br}$ Med J 1975; ii: 179-83.

10 Blamey SL, Imrie CW, O'Neill J, Gilmour WA, Carter DC. Prognostic factors in acute pancreatitis. Gut 1984; 25: $1340-6$.

11 Silverstein W, Isikoff MB, Hill MC, Barkin J. Diagnostic imaging of acute pancreatitis: prospective study using CT and sonography. AJR 1981; 137: 497-502 .

12 Nordestgaard AG, Wilson SE, Williams RA. Early computerised tomography as a predictor of outcome in acute pancreatitis. Am J Surg 1986; 152: 127-32.

13 Block S, Maier W, Clausen C, Buchler M. Melfertheiner P. Beger HG. Diagnostik der nekrotisicrenden pankreatitis. Dtsch Med Wochenschr 1985; 110: 826-7.

14 Spechler JS, Dalton JW, Robbins AH, et al. Prevalence of normal serum amylase levels in patients with acutc alcoholic pancreatitis. Dig Dis Sci 1983; 28: 865-9.

15 Moossa AR. Diagnostic tests and procedures in acute pancreatitis. N Engl J Med 1984; 311: 639-43.

16 Weill FS. Controversies in acute pancreatitis. 1st ed. New York: Springer Verlag, 1981: 59-63.

17 Ponette E, Pringot J, Baert AL, Marchal G, Dardenne AN, Coenen Y. Computerized tomography and ultrasonography in acute pancreatitis. Acta Gastroenterol Belg 1976; 34: 402-4.

18 Butzelaar RM, Mulder GL, Kuhler WJ, Bayink PD. Davies G. Computer tomography in acute pancreatitis. Acta Radiol [Diagn] (Stockh) 1978; 19: 417-22.

19 Kivisaari L, Virtama P, Rantakokko Y. Computerised tomography of the pancreas with acute pancreatitis. Ann Clin Res 1979; 11: 90-3. 
20 Dembner AG, Jaffe CC, Simeone J, Walsh J. A new computed tomographic sign of pancreatitis. AJR 1979; 133: 477-9.

21 Mendez G, Isikoff MB, Hill MC. CT of acute pancreatitis: interim assessment. AJR 1980; 135: 463-9.

22 Jeffrey RB, Federle MP, Cello JP, Crass RA. Early computed tomographic scanning in acute severe pancreatitis. Surg Gynecol Obstet 1982; 154: 170-4.

23 Frija J, Abonou A, Viandier A, Laval-Jeantet M. Tomodensitometric des pancreatites aigues graves. J Radiol 1983; 64: 483-8.

24 Rohner A, Hauser $\mathrm{H}$. Bilan tomometrique dans la pancreatite aiguc. Lyon Chirurgical 1983; 79: 313-8.

25 Kalmar JA, Matthews CC, Bishop LA. Computerized tomography in acute and chronic pancreatitis. South Med J 1984; 77: 1393-5.

26 Clavien PA, Hauser H, Meyer P, Rohner A. Value of contrast-enhanced computerized tomography in the carly diagnosis and prognosis of acute pancreatitis. Am J Surg 1988; 155: 457-66.

27 Andrade HH, Zazucta AH, Castellanos AZ, Gonzalez RB. Tomografia axial computada diagnostico de pancreatitis aguda. Rev Gastroenterol Mex 1984; 49: 31-7.

28 Hill MC, Barkin J, Isikoff MB, Silverstein W, Kalser M. Acute pancreatitis: clinical vs CT findings. AJR 1982; 139: 263-9.

29 Balthazar EJ, Ranson JH, Naidich DP, Megibow AJ, Caccavale R, Cooper MM. Acute pancreatitis: prognostic value of CT. Radiology 1985; 156: 767-72.

30 McKay AJ, Imrie CW, O’Neill J, Duncan JG. Is an early ultrasound scan of value in acute pancreatitis? Br J Surg 1982; 69: 369-72.

31 Neoptolemos JP, Hall AW, Finlay DF, Berry JM, CarrLocke DL. Fossard DP. The urgent diagnosis of gallstones in acute pancreatitis: a prospective study of three methods. Br J Surg 1984; 71: 230-3.

32 Goodman AJ, Neoptolemos JP, Carr-Locke DL, Finlay DBL, Fossard DP. Detection of gallstones after acute pancreatitis. Gut 1985; 26: 125-32.

33 Anderson JA, Morran CG, Anderson JR, Carter DC. Acute pancreatitis and non-Hodgkin's lymphoma. Postgrad Med J 1987; 63: 137-9.

34 Trapnell $\mathbf{J}$. The natural history and management of acute pancreatitis. Clin Gastroenterol 1972; 1: 147-66.

35 Weissberg D, Adam YG, Volk H, State D. Acute pancreatitis: a 10 year study. Am Surg 1972; 38: 574-81.

36 Imrie CW, Whyte AS. A prospective study of acute pancreatitis. Br J Surg 1975; 62: 490-4.

37 Levine E. Carcinoma of the pancreas presenting as acute pancreatitis: CT diagnosis. Gastrointest Radiol 1981; 29: 29-33.

38 Schroder T, Kivisaari L. Standertskjold-Nordenstam CG, et al. Pancreatic blood flow and contrast enhancement in computed tomography during experimental pancreatitis. Eur Surg Res 1985; 17: 286-91.

39 Nuutinen P. Contrast-enhanced computed tomography in acute oedematous pancreatitis. Surg Res Comm 1987; 1: 251-9.

40 Kivisaari L, Somer K, Standertskjold-Nordenstam CG. et al. Early detection of acute fulminant pancreatitis by contrast-enhanced computed tomography. Scand J Gastroenterol 1983; 18: 39-41.
41 Kivisaari L, Somer K. Standertskjold-Nordenstam CG, et al. A new method for the diagnosis of acute haemorrhagic-necrotizing pancreatitis using contrastenhanced CT. Gastrointest Radiol 1984; 9: 27-30.

42 Grabbe VE, Damman HG, Heller M. Klert der computertomographie fur die prognose der akuoten pankreatitis. Fortschr Roentgenstr 1982; 136: 534-7.

43 Block S. Maier W, Bittner R. Buchler M. Malfertheiner $P, B e g e r$ HG. Identification of pancreatic necrosis in severe acute pancreatitis: imaging procedures versus clinical staging. Gut 1986; 27: 1035-42.

44 Kursawe K, Luning M, Wolff H, Mai A. Ergebnisse der computer-tomographischen diagnostik zur differenzicrung des schweregrades der akuten pankreatitis. Fortschr Roentgenstr 1987; 146: 27-33.

45 Becker H, Gahbauer H, Horn J, Mechler Th. Korrelation klinischer und computertomographischer betune fur die therapie und prognose der akuten pankreatitis. Chirug 1985; 56: 386-92.

46 Robert JH, Mcyer P. Rohner A. Can serum and peritoneal amylase and lipase help in the early prognosis of acute pancreatitis. Ann Surg 1986; 203: 163-8.

47 Schroder T, Kivisaari L, Somer K. StandertskjoldNordenstam CG, Kivilaakso E, Lempinen M. Significance of extrapancreatic findings in computed tomography (CT) of acute pancreatitis. Eur J Radiol 1985; 5: 273-5.

48 Takada T, Yasuda H, Uchiyama K, Hasegawa H, Sitaka J. Nagai J. CT findings and CT score in acute pancreatitis compared with severity. Nippon Igaku Hoshasen Gakkai Zasshi 1986; 46: 1167-73.

49 Cuschieri A, Wood AB, Cumming JRG, Meehan SE, Mackie CR. Treatment of acute pancreatitis with fresh frozen plasma. BrJ Surg 1983: 70: 710-2.

50 Bradley EL. Gonzalez AC. Clements JL. Acute pancreatic pseudocysts: incidence and implications. Ann Surg 1976; 184: 734-7.

51 Proctor HJ, Schwartz JA, Rutledge R, Mauro MA. Radiology and surgery in the treatment of the complications of acute pancreatitis. NC Med J 1987; 48: $211-6$.

52 Kolmannskog F. Kolbenstredt A. Aakhus T. Computed tomography in inflammatory mass lesions following acute pancreatitis. J Comput Assist Tomogr 1981; 5: 169-71.

53 Crass RA, Meyer AA, Jeffrey RB, et al. Pancreatic abscess: impact of computerised tomography on carly diagnosis and surgery. Am J Surg 1985; 150: 127-31.

54 Mendez G. Isikoff MB. Significance of intrapancreatic gas demonstrated by CT: a review of nine cases. $A J R$ 1979; 132: 59-62.

55 Ranson JHC, Balthazar E, Caccavale R, Cooper M. Computed tomography and the prediction of pancreatic abscess in acute pancreatitis. Ann Surg 1985; 201: 65665.

56 Alexander ES, Clark RA, Federle MP. Pancreatic gas: indication of pancreatic fistula. AJR 1982; 139: 1089-93.

57 Torres WE. Clements JL. Sones PJ, Knopf DR. Gas in the pancreatic bed without abscess. $A J R$ 1981; 137: 1131-3.

58 Hill MC, Dach JL, Barken J. Isikoff MB, Morse B. The role of percutaneous aspiration in the diagnosis of pancreatic abscess. AJR 1983: 141: 1035-8. 